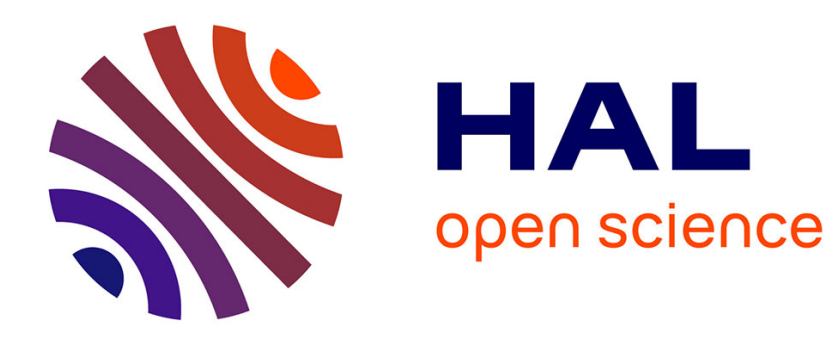

\title{
Lessons From In Situ Experiments during French Elections
}

Jean-François Laslier

\section{To cite this version:}

Jean-François Laslier. Lessons From In Situ Experiments during French Elections. 2009. hal00432397

\author{
HAL Id: hal-00432397 \\ https://hal.science/hal-00432397 \\ Preprint submitted on 16 Nov 2009
}

HAL is a multi-disciplinary open access archive for the deposit and dissemination of scientific research documents, whether they are published or not. The documents may come from teaching and research institutions in France or abroad, or from public or private research centers.
L'archive ouverte pluridisciplinaire HAL, est destinée au dépôt et à la diffusion de documents scientifiques de niveau recherche, publiés ou non, émanant des établissements d'enseignement et de recherche français ou étrangers, des laboratoires publics ou privés. 


\section{ECOLE POLYTECHNIQUE}

CENTRE NATIONAL DE LA RECHERCHE SCIENTIFIQUE

LESSONS FROM IN SITU EXPERIMENTS DURING FRENCH ELECTIONS

Jean-François LASLIER

November 2009

Cahier $n^{\circ} 2009-43$

\section{DEPARTEMENT D'ECONOMIE}

Route de Saclay

91128 PALAISEAU CEDEX

(33) 169333033

http://www.enseignement.polytechnique.fr/economie/

mailto:chantal.poujouly@polytechnique.edu 


\title{
Lessons From In Situ Experiments during French Elections
}

\author{
JF Laslier \\ Département d'Economie, Ecole Polytechnique \\ 91128 Palaiseau, France
}

November 15, 2009

\section{Introduction}

In 2002 and 2007, during the French presidential elections, several experiments have taken place, designed to test the reaction of the public to new voting rules. What have we learned from them so far ? These experiments are of a rather original nature and raise several methodological issues with respect to their design and to the analysis of their results. In order to assert what can be learned and what cannot be learned, I will discuss the methodological issues at stake. I will in particular show that the conclusions to be derived from such experiments are very sensitive to some details of the protocol and also to some details of the voting rules under scrutiny.

The main goal of these experiments is the comparative study of voting rules. Therefore the closest precedents are (a) comparative studies of voting rules across countries/time ; (b) some rare comparative studies of voting rules within one election ; (c) laboratory experiments on voting rules. Point (a) is a major trend in Political Science. It mixes the questions of voter behavior and party behavior, which is certainly a virtue from the point of view of realism but a problem for scientific analysis. By definition, (a) is not interested in non-existing voting rules. Point (b) is rare, one example being the study done during the election of the council of the Social Choice and Welfare society in $1999^{1}$. Point (c) is also rare but we now have some studies of this type: Forsythe et al. (1993, 1996), Blais et al (2007, 2008, 2009), Béhue et al. (2009), Kube and Puppe (2009).

\footnotetext{
${ }^{1}$ See Brams and Fishburn (2001), Saari (2001) and Laslier (2003). The survey Brams and Fishburn (2006) contains discussions of various instances of Approval Voting which can be considered as somehow in between observation and experimentation.
} 
A complete description of the protocol of these "live experiments" will be provided in the next section ${ }^{2}$ but two main points should be mentioned now:

- Participating to such an experiment has no direct consequence. Such is also the case in opinion survey, and experiments are a priori facing the same methodological difficulties as survey research. In particular the participation bias might be important. Correcting for the bias is more difficult than in a survey because we do not know the personal characteristics of each respondent, see section 5. On that point, these "live" or "in situ" experiments should be contrasted with laboratory experiments that follow the standards of experimental economics, in which participants incentives are controlled through monetary rewards. ${ }^{3}$

- The experience uses the decorum and etiquette of a true election. In particular, open participation, anonymity and confidentiality are guaranteed to the participants. This is different from pool surveys and from laboratory experiments. The event is also presented like a scientific test of a voting rule, and not like an exit pool. It seems reasonable (although we have no absolute proof of that) to think that this framing lowers the participation and observation biases.

This kind of experiments raises several methodological problems :

1. There is obviously no control of the political supply. The situation is similar to comparative analysis since the political situation can only be the real one, but the political situation does not vary and thus no comparison is done!

2. There is no control of the sample. The protocol described above imposes that participants cannot be selected, so the only selection is self-selection.

3. Each observation is relatively poor, because an observation is just one anonymous ballot from a pooling station. Even if ballots are complex as

\footnotetext{
${ }^{2}$ The original papers are: Balinski et al.(2003), Balinski and Laraki (2007), Baujard and Igersheim (2007), Laslier and Van der Straeten (2002, 2004, 2008). See also a similar experiment on Approval Voting made in the town of Messel (Germany) by Alos-Ferrer and Granic (2009), during the 2008 state elections in Hesse.

${ }^{3}$ Principles of experimental economics are explained in Davis and Holt (1993). For experiments in Political Science, see Green and Gerber (2002). Examples of experiments on voting include Fiorina and Plott (1978), McKelvey and Ordeshook (1990), Wantchekon (2003).
} 
are ballots of approbation, ranking or evaluation, no other individual characteristic is known. ${ }^{4}$

4. We do not know exactly what is the voter's understanding of the voting rule. If the voting rule on test is complex, then some voters may not know how the ballots will be counted.

5. There are potential ethical problems in case some voter understand incompletely or even wrongly the voting rule itself or the goal of the experiment.

The methodological problems are related on one hand to difficulties for the voter to complete the task and to understand the voting rule and the experiment; and on the other hand to difficulties for the researcher to reach sound conclusions on the basis of the collected data. The next section describe the experiments. The two following ones are devoted to the problems on the voters side (Section 3) and to the analytical difficulties (Section 4).

\section{Description of the experiment}

I here describe the experiment made on April 21, 2001, during the first round of the French presidential election. Recall that the French presidential election is a runoff system. If a candidate gets at least $50 \%$ of the votes in the first round, he or she is elected. If no candidate gets at least $50 \%$ of the score (which is usually the case), the first two candidates meet in a runoff round. Who gets the majority of the votes in this second round is elected. In 2001, 16 candidates were vying. Jacques Chirac (Rassemblement pour la République, conservative) came first. He was followed by Jean-Marie Le Pen (Front National, nationalistic law-and-order movement) and the former prime minister Lionel Jospin (Parti Socialiste) came third. This event was a big surprise. I first describe the experimental protocol, and then give some elementary statistics about the obtained data.

\subsection{The protocol}

The experiment was run in six voting places: the single voting post of the village of Gy-les-Nonains (Loiret) and five (out of twelve) voting posts in the city of d'Orsay (Essonne). Gy has 482 registered voters and the five voting

\footnotetext{
${ }^{4}$ Baujard and Igersheim (2007) slightly move away from this methodology by asling participants to fill questionaires.
} 
posts in Orsay include 4,237 registered voters. We were kindly helped by the people locally in charge of the organization of the election.

One week before the election day, we sent to each registered voter a letter at his/her personal address. The voting rule to be tested (Approval Voting, with no runoff) was explained, we carefully explained that the experiment was done for scientific purpose and would not interfere with the official vote, and we asked for their kind participation. The same information was provided in the municipal bulletin.

On the day of the election, we set specific voting booths, tables, and urns, in the same room (or in an adjacent room) where the official vote was taking place. After voting for the official vote, the voter was invited to proceed to participate to the experiment.

He or she received an approval voting ballot paper with the names of all candidates and could fill it and return it anonymously.

Everything in fact was designed to mimic the official voting procedure. Note that only the voters who turned out for the official vote were able to participate to the experiment.

\section{$2.2 \quad$ Some statistics}

In France, almost every citizen above 18 is registered as a voter. The ratio of votes to registered voters measures the turn out. Turn out may be high for the presidential election. Participants to the experiment all came to vote for the official vote, so the participation rate at the experiment is defined as the percentage of participants among the voters who were present on this day.. Voters' reaction to the experiment was generally favorable and high participation rates were observed: about $75 \%$ in Orsay and more than $90 \%$ in Gy-les-Nonains. Table 1 provides these figures.

\begin{tabular}{|c|c|c|c|c|}
\cline { 3 - 5 } \multicolumn{2}{c|}{} & Gy & Orsay & All \\
\hline \hline Official & Registered voters & 482 & 4237 & 4719 \\
\cline { 2 - 5 } & Votes cast & 395 & 2951 & 3346 \\
\cline { 2 - 5 } & Turn out rate & $82.0 \%$ & $69.6 \%$ & $70.9 \%$ \\
\hline \hline \multirow{2}{*}{ Experimental } & Participants & 365 & 2232 & 2597 \\
\cline { 2 - 5 } & Participation rate & $\mathbf{9 2 . 4 \%}$ & $\mathbf{7 5 . 6 \%}$ & $\mathbf{7 7 . 6 \%}$ \\
\hline
\end{tabular}

Table 1: Participation at the experiment

On average, a voter approved of 3.15 candidates, out of 16 . The distribution around this value is rather smooth, as can be seen in Table 2. One can notice that one-name ballots are not over-represented. 


\begin{tabular}{|r|r|r|r|r|r|r|r|r|r|r|r|}
\hline \multicolumn{10}{|c|}{ Average number : 3,15 out of 16} \\
\hline 0 & 1 & 2 & 3 & 4 & 5 & 6 & 7 & 8 & 9 & 10 & $>10$ \\
\hline 36 & 287 & 569 & 783 & 492 & 258 & 94 & 40 & 16 & 6 & 1 & 5 \\
\hline
\end{tabular}

Table 2: Number of approved candidates

In order to give a flavor of the data obtained from this experiment, Tables 3 provides the "association matrix" for one voting post (Gy-les-Nonains). In this symmetric matrix, candidates are in line and in collumn. In the cell corresponding to candidates $A$ and $B$ is indicated the number of voters who approved both $A$ and $B$. In the diagonal are the candidates' approval scores. For instance, 139 participants approved Jacques Chirac (Jc), and the number 51 at the intersection of the line Jc and the column LP means that 51 participants approved both Jacques Chirac and Jean-Marie Le Pen.

\begin{tabular}{|l|l|l|l|l|l|l|l|l|l|l|l|l|l|l|l|l|}
\hline & $\mathrm{Jc}$ & $\mathrm{Lp}$ & $\mathrm{Lj}$ & $\mathrm{Fb}$ & $\mathrm{Al}$ & $\mathrm{Jp}$ & $\mathrm{Nm}$ & $\mathrm{Ob}$ & $\mathrm{Js}$ & $\mathrm{Am}$ & $\mathrm{Rh}$ & $\mathrm{Bm}$ & $\mathrm{Ct}$ & $\mathrm{Cl}$ & $\mathrm{Cb}$ & $\mathrm{Dg}$ \\
\hline $\mathrm{Jc}$ & 139 & 51 & 15 & 47 & 10 & 28 & 11 & 10 & 36 & 48 & 3 & 31 & 5 & 9 & 6 & 3 \\
\hline $\mathrm{Lp}$ & 51 & 119 & 10 & 22 & 18 & 17 & 9 & 13 & 21 & 22 & 5 & 44 & 3 & 5 & 4 & 4 \\
\hline $\mathrm{Lj}$ & 15 & 10 & 87 & 14 & 21 & 17 & 40 & 24 & 11 & 5 & 26 & 0 & 23 & 9 & 5 & 4 \\
\hline $\mathrm{Fb}$ & 47 & 22 & 14 & 85 & 10 & 25 & 13 & 9 & 10 & 33 & 3 & 13 & 8 & 14 & 7 & 2 \\
\hline $\mathrm{Al}$ & 10 & 18 & 21 & 10 & 64 & 13 & 19 & 24 & 10 & 3 & 18 & 6 & 11 & 11 & 7 & 12 \\
\hline $\mathrm{Jp}$ & 28 & 17 & 17 & 25 & 13 & 67 & 10 & 11 & 10 & 19 & 2 & 7 & 8 & 11 & 4 & 3 \\
\hline $\mathrm{Nm}$ & 11 & 9 & 40 & 13 & 19 & 10 & 67 & 32 & 7 & 9 & 15 & 3 & 15 & 10 & 4 & 12 \\
\hline $\mathrm{Ob}$ & 10 & 13 & 24 & 9 & 24 & 11 & 32 & 62 & 10 & 8 & 16 & 9 & 16 & 13 & 3 & 15 \\
\hline $\mathrm{Js}$ & 36 & 21 & 11 & 10 & 10 & 10 & 7 & 10 & 74 & 18 & 5 & 13 & 5 & 6 & 6 & 4 \\
\hline $\mathrm{Am}$ & 48 & 22 & 5 & 33 & 3 & 19 & 9 & 8 & 18 & 77 & 2 & 15 & 4 & 10 & 6 & 3 \\
\hline $\mathrm{Rh}$ & 3 & 5 & 26 & 3 & 18 & 2 & 15 & 16 & 5 & 2 & 37 & 0 & 5 & 4 & 3 & 7 \\
\hline $\mathrm{Bm}$ & 31 & 44 & 0 & 13 & 6 & 7 & 3 & 9 & 13 & 15 & 0 & 62 & 1 & 2 & 4 & 4 \\
\hline $\mathrm{Ct}$ & 5 & 3 & 23 & 8 & 11 & 8 & 15 & 16 & 5 & 4 & 5 & 1 & 33 & 7 & 4 & 3 \\
\hline $\mathrm{Cl}$ & 9 & 5 & 9 & 14 & 11 & 11 & 10 & 13 & 6 & 10 & 4 & 2 & 7 & 36 & 5 & 4 \\
\hline $\mathrm{Cb}$ & 6 & 4 & 5 & 7 & 7 & 4 & 4 & 3 & 6 & 6 & 3 & 4 & 4 & 5 & 21 & 1 \\
\hline $\mathrm{Dg}$ & 3 & 4 & 4 & 2 & 12 & 3 & 12 & 15 & 4 & 3 & 7 & 4 & 3 & 4 & 1 & 26 \\
\hline
\end{tabular}

Table 3: Association matrix at Gy-les-Nonains

Table 4 provides the relative candidate scores in the experiment and the official vote. Notice that the approval scores can be expressed either in proportion of the number of ballots or in proportion of the total number of approvals. In the second case the sum of percentages is 100. The two computations are equivalent up to the ratio of total approvals to total ballots, 
that is the average number of approvals per ballot.

\begin{tabular}{|l|l|l|l|}
\hline \multirow{2}{*}{} & \multicolumn{2}{|c|}{ Experiment "Approval Voting " } & \multicolumn{1}{|c|}{ Official score } \\
\cline { 2 - 4 } & $\%$ ballots. & $\%$ approvals & $\%$ ballots \\
\hline J. Chirac & $38.19 \%$ & $13.16 \%$ & $19.64 \%$ \\
\hline J.-M. Le Pen & $32.69 \%$ & $11.27 \%$ & $19.64 \%$ \\
\hline L. Jospin & $23.90 \%$ & $8.24 \%$ & $11.11 \%$ \\
\hline F. Bayrou & $23.35 \%$ & $8.05 \%$ & $6.72 \%$ \\
\hline A. Laguiller & $17.58 \%$ & $6.06 \%$ & $13 \%$ \\
\hline J.-P. Chevènement & $18.41 \%$ & $6.34 \%$ & $4.65 \%$ \\
\hline N. Mamère & $18.41 \%$ & $6.34 \%$ & $4.65 \%$ \\
\hline O. Besancenot & $17.03 \%$ & $5.87 \%$ & $2.84 \%$ \\
\hline J. Saint-Josse & $20.33 \%$ & $7.01 \%$ & $9.56 \%$ \\
\hline A. Madelin & $21.16 \%$ & $7.29 \%$ & $5.17 \%$ \\
\hline R. Hue & $10.16 \%$ & $3.50 \%$ & $3.10 \%$ \\
\hline B. Mégret & $17.03 \%$ & $5.87 \%$ & $2.84 \%$ \\
\hline C. Taubira & $9.07 \%$ & $3.12 \%$ & $0.52 \%$ \\
\hline C. Lepage & $9.89 \%$ & $3.41 \%$ & $2.84 \%$ \\
\hline C. Boutin & $5.76 \%$ & $1.99 \%$ & $0.78 \%$ \\
\hline D. Gluckstein & $7.14 \%$ & $2.46 \%$ & $1.81 \%$ \\
\hline Total & $290.11 \%$ & $100 \%$ & $100 \%$ \\
\hline
\end{tabular}

Table 4: Candidate scores at Gy-les-Nonains. Average number of aproval per ballot is 2.90

Tables like these ones are the data obtained from in situ experiments. This kind of data has been used by Laslier and Van der Straeten (2002, 2004), Baujard and Igersheim (2007) or Laslier (2008); see Section 4.

\subsection{Replications}

This protocol was first fine-tuned and tested in a pilot experiment with students at Sciences Po Paris by Balinski, Laslier and Van der Straeten in January 2002 where we tested for two voting rules: Approval Voting and Range Voting with the 0-10 scale. It was then used by Balinski, Laraki, Laslier and Van der Straeten during the 2002 presidential election, as explained above.

During the 2007 presidential election, several teams more or less replicated the same protocol. Baujard and Igersheim tested for Approval Voting and for Range Voting with grades 0,1 and 2. They also had some participants filling a questionnaire about the experiment. (Baujard and Igersheim 
2007.) Balinski and Laraki tested for an evaluative method they call the "majority judgement." Farvaque, Jayet and Ragot (2009) asked voters to rank-order the candidates as a test of Single Transferable Vote.

In Germany Alós-Ferrer and Granić (2009) tested Approval Voting

\section{Voter's difficulties}

The question of the voter's understanding of a voting rule is delicate because it must be raised at different levels. The first level is : How to materially fill the ballot? The second level is : How will the paper ballots be counted ? The third level is : What are the implications of that particular balloting procedure ? During the experiments, participants ask for explanations at these different levels. Some participants claim that "they do not understand." Nevertheless, the vast majority, if asked, answer that "they understand." Further discussion shows that any of the three above questions can trigger a positive or negative answer to the question "Do I understand the experiment?"

\subsection{Difficulties to complete the task}

Almost all voters understand that they are asked to make marks, give points, or chose adjectives. In many cases, this knowledge will be sufficient to trigger an affirmative answer to the question "Do you understand ?"

A specific problem arises for voting rules in which voters grade candidates, with ordinal or cardinal grades. In the pilot experiment at Science Po made by Balinski, Laslier and Van der Straeten on January 23, 2002, the average evaluation of candidates on the $0-10$ scale was 2.21 points, but that figure may be misleading since many grades were 0 . Out of the $408 \times 15=6120$ recorded grades, about half of them are 0 . Many ballots included simultaneously candidates with the 0 grade and candidates without any grade. This seems to indicate that giving a 0 grade and not grading may have two different meanings for the voter. We, nevertheless, had precisely indicated on the ballot that not grading a candidate will be counted as a 0 grade. The same problem potentially arises in the experiment of Baujard and Igersheim (2007) with the $0-1-2$ scale and the additive rule.

How to solve this problem? A possibility is computing not exactly the sum of the points obtained by the candidate (or, equivalently, the average with respect to the total number of voters) but the average with respect to the number of voters who have effectively graded the candidate. This is mathematically equivalent to replacing the missing grades of a candidate 
by the average of the observed grades of the considered candidate. This is impossible to justify. It might have in practice the odd consequence that candidates who are almost unknown will have the best grades because they tend to be known by their supporters rather than by their opponents. Therefore this is clearly not a good solution.

A reasonable solution to this problem is to explain to the voters that they are not asked to evaluate the candidates but to give points to the candidates. This is what happens in Approval Voting, and it apparently causes no misunderstanding. More detailed grading systems can be presented in the same manner if the electoral rule is that a candidate finally receives the total of points given to him or her by all the voters, such as the case in "cumulative" voting, in "range" voting, or in "le vote par note."

The difference between saying "You are to evaluate the candidates. The candidate who will receive the largest average evaluation will be elected" and saying "You are to give points to candidates. The candidate who will receive the most points will be elected" is obsolete but is relevant. The second formulation is more concrete, which is always a good thing for an explanation. It is also neutral because it is purely factual and does not pre-suppose or impose any interpretation of the voter's action. The word "evaluation" is closer to a particular interpretation of the meaning of the vote. But the voter is free to give any meaning to her/his vote. She/he might want to give many points to a candidate she/he does not value much. Why not? That is obviously her/his right and the legislator must not make a confusion between the statement of the electoral rule and the interpretation of people's action. Therefore, as well as for the practical reason mentioned above, explanations should be as factual as possible. Baujard and Igersheim (2007) have carefully analyzed the spoiled ballots and missing grades in their data. They conclude that with the $0-1-2$ scale and the simple counting rule, voters have no difficulties in completing the task.

When voters are asked to rank-order all candidates, they usually have no problem in ranking the main candidates, but have a problem for the other ones. This may cause serious problems for the Borda rule and other rank-based methods such as Alternative vote (STV) with the Hare or the Coombs system of transfers. Another problem is that, in practice, to rankorder a large set of candidate is a complicated task. This is a well-known problem in countries where these systems are in use. A practical solution to this "over-long ballot paper" problem is to let the voter follow some prespecified ranking agreed by political parties, as done for instance for the Australian Senate election (see Farrell 2001).

When grades are presented as adjectives, as in Balinski and Laraki 
(2007), the confusion between a missing grade and the worst evaluation is not justified since the use of adjectives is intended to impose "true" meaning to the grades on top of what they actually are: being counted in the maximum-median calculus.

\subsection{Voter's understanding of the voting rule per se}

One may conclude that, apart from the (potentially important) question of the missing grades, participants have no difficulties completing the material task asked. In that sense, voters can answer "Yes" to the question "Do you understand". But of course one should not infer from such an answer that the voter has understood correctly how the ballots will be counted. The voter may be unaware that there are different, non-equivalent, ways to count complex ballots, because this fact is seldom known in the general public. And even if she/he is aware of this fact, for instance because she/he has read documents about the experiment before the election day, she/he may have nevertheless failed to grasp the details, for different reasons.

This problem is of variable importance for different voting rules. At one extreme, there can hardly be any misunderstanding with simple counting procedures like FPTP or AV, so that one-sentence explanations are sufficient to avoid any misunderstanding. At the other extreme, complex ballots demanding ranks, scores, or grades can be counted in many different ways so that one cannot trust that the participants to the experience have understood the voting rule.

The solution to this problem, following the standard good practice in experimental economics, is to show very concretely how ballots are counted before proceeding to the experiment, and to make sure that participants have assimilated the counting process. This is possible in the laboratory even with rules as complex as Alternative Vote with the Hare system of transfers, as noticed by Blais et al. (2009). But this is unfortunately not feasible during the kind of "live" experiments at hand. Consequently, we must face the possibility that many voters who participated to the 2007 experiments on STV or "le jugement majoritaire" were simply not understanding how ballots were counted. Two questions emerge: Why would individuals participate to something they do not understand? Is that so important?

Anyone who participated in 2002 or in 2007, as a voter or as an experimentalist, to these events noted that they are quite pleasant. The atmosphere is rather friendly, most people seem rather happy to participate and, in addition, such an event is a positive social event. We know from the experiments of Gerber, Green and Larimer (2008) that the social pressure 
is a very important determinant of turnout. Indeed positive social pressure seems to have been high during these experiments, in particular in some places (it may explain the extraordinary $92.4 \%$ participation rate in the small village of Gy-les-Nonains). It is therefore very likely that some voters participate to the experiments even without a good understanding of the voting rule at stake, when the voting rule is complex.

Is it important, for these experiments, that voters have an exact and clear understanding of how ballots are counted ? Obviously yes, this point is crucial, for at least two different reasons.

1. Voting behavior may be different depending on the voting rule. Political science has taught us that people may not use single-name ballots the same way in One-round FPTP, Two-round, or PR elections. Economic theory has explained that rational behavior in voting is also sensitive to the details of the voting rule. Therefore, from the methodological point of view, if the objective is to learn about voters' behavior, and later to compare voting rules, it is essential to make sure that the voting rule itself is well understood.

2. If some participants do not understand clearly the voting rule and realize that they don't, they may have the impression that the scientists have hidden something on purpose. The same thing happens for a voter who first thinks she/he has well understood and later discover that she/he had not. Deceiving the participants when doing experiments about democracy should certainly be avoided. The risk is a loss of trust towards scientific work in politics. The worst thing that could happen is that scientists present themselves as "those who understand a complex voting rule" in front of "those who do not have to understand" but are asked to cooperate.

Not cheating is important with respect to both professional ethics and methodology.

\subsection{Voter's understanding of the consequences of the voting rule}

A third level of comprehension has to do with the implication for Politics of the proposed voting rule. It is noticeable that some participants immediately skip to this level. For instance, one participant would comment (about Approval Voting) "Yes, I understand what you do. This is to give voice to the small candidates." In that case, we are facing a problem opposite to the previous one: over-confident participants believe they know, or believe we know, something which is far from being established.

The same mechanism may result in a negative opinion with respect to the 
idea of experimentation following a "You are playing with fire" comment of argumentation. I heard this reasoning several times in 2001 from scholars and officials when looking for places to perform the 2002 experiment. Generally, we experiment in order to learn things we do not know. The fact that we do not know in advance the result of an experiment should obviously not be considered as a problem, as long as we do not try to make the public believe that we already know what is good and what is not.

On that issue, there is no doubt that all these experiments are very positive. The general public seems both reasonable and respectful when it comes to the idea of experimenting new voting rules, even more reasonable and respectful than learned scholars. ${ }^{5}$ This is one more reason not to deceive.

\section{Analyzing the results}

The collected data is difficult to analyze because of possibly important biases due to the specific experimental protocol. This point is discussed in the next section. But this difficulty should not hide the richness of the collected data, which is amenable to original and insightful analysis, as explained in section 4.2 .

\subsection{The participation bias}

The participation bias in those kind of events may be huge. In the pilot experiment of January 23, 2002, the approbation rate of Chirac was 33.58 $\%$ whereas the approbation rate of Jospin was $61.76 \%$, which probably reflects a strong leftist bias among participants.

Table 5 deals with the six voting stations where the experiment was done in 2002. It provides the number of voters at the official vote, the number of Le Pen's official votes. Voting stations are ordered according to Le Pen's score in percentage. The two last lines indicate the participation rate at the experiment, and the number of approvals in favor of Le Pen. We can see in Orsay an inverse correlation between the participation rate and Le Pen's support. it is for instance remarkable that in Orsay 12, 88 voters voted for Le Pen at the official vote but 63 voters approved Le Pen at the experimental

\footnotetext{
${ }^{5}$ In 2002, a priori negative opinions about these experiments were held by some colleagues, and some elected officials. They predicted very low participation rates, based on their own claimed experience in organizing public consultation on local issues. Some were reluctant to the very idea of experimentation in the field of politics, arguing that, by principle, one should not mix serious political matters with adventurous ideas.
} 


\begin{tabular}{|l|c|c|c|c|c|c|}
\hline$(2002)$ & Gy & Or. 12 & Or. 6 & Or. 7 & Or. 1 & Or. 5 \\
\hline Voters & 395 & 622 & 607 & 635 & 522 & 565 \\
\hline \multirow{2}{*}{ LePen votes } & 76 & 88 & 49 & 45 & 35 & 35 \\
& $19.2 \%$ & $14.1 \%$ & $8.1 \%$ & $7.1 \%$ & $6.7 \%$ & $6.2 \%$ \\
\hline Participation & $92.4 \%$ & $66.7 \%$ & $75.8 \%$ & $55.3 \%$ & $78.3 \%$ & $84.2 \%$ \\
\hline \multirow{2}{*}{ LePen approvals } & 119 & 63 & 55 & 38 & 52 & 51 \\
& $32.6 \%$ & $15.2 \%$ & $12.0 \%$ & $8.1 \%$ & $12.7 \%$ & $10.7 \%$ \\
\hline
\end{tabular}

Table 5: Participation biais in 2002 experiments

vote. In that respect, the results obtained in the small village of Gy-LesNonains are important because the participation is almost complete here, even if the extreme right vote is more important in this village than it is in the city of Orsay.

Some apparent conclusions from gross figures, such as the idea that some voting systems like approval voting, favors the center and are detrimental to extreme candidates, may be highly sensitive to participation bias. To tackle this problem Laslier and Van der Straeten (2004) have built a model that relates single-name ballots to approval ballots. The idea is that voters never vote for a candidate they do not approve, and that the probability that a given voter votes for the candidate $c$ when she approves the set $B$ of candidates including $c$, is proportional to some parameter which depends on $c$ only. This parameter is called the single-name lever of $c$. This model can be estimated and used to correct, as much as possible, for participation bias, and then extrapolated to the entire country in order to draw general conclusions.

The second column of Table 6 shows estimates for the candidates' levers (normalized to 1 for Chirac). These values show how some candidates, in particular Jean-Marie Le Pen and Jacques Chirac were more than the others able to convert the voters' approval into a first round vote.

Knowing the probability that a voter who voted for candidate $i$ in the official election approved of candidate $j$ in the approval voting experiment, and given national scores in the official election, one can extrapolate the result of the experiment to the national level. The last two columns of Table 6 shows extrapolations of the results from Gy and Orsay to France, and the candidates' true national scores. It is to note that the main political event of this election was the Extreme Right candidate Le Pen defeating the former prime minister Jospin. While Jacques Chirac would have still been elected president, the striking observation in Table 6 is that the extrapolation pre- 


\begin{tabular}{|l|r|r|r|}
\cline { 2 - 4 } \multicolumn{1}{c|}{} & \multicolumn{3}{c|}{ France } \\
\cline { 2 - 4 } \multicolumn{1}{c|}{} & Levers & approval & first round \\
\hline Chirac & 1 & $36.7 \%(1)$ & $19.9 \%(1)$ \\
\hline Le Pen & 1.16 & $25.1 \%(4)$ & $16.9 \%(2)$ \\
\hline Jospin & .73 & $32.9 \%(2)$ & $16.2 \%(3)$ \\
\hline Bayrou & .49 & $27.1 \%(3)$ & $6.8 \%(4)$ \\
\hline Laguiller & .38 & $16.8 \%(9)$ & $5.7 \%(5)$ \\
\hline Chevènement & .43 & $22.4 \%(6)$ & $5.3 \%(6)$ \\
\hline Mamère & .39 & $24.3 \%(5)$ & $5.2 \%(7)$ \\
\hline Besancenot & .19 & $17.6 \%(8)$ & $4.2 \%(8)$ \\
\hline Saint-Josse & .88 & $13.5 \%(11)$ & $4.2 \%(9)$ \\
\hline Madelin & .36 & $20.4 \%(7)$ & $3.9 \%(10)$ \\
\hline Hue & .53 & $11.3 \%(14)$ & $3.4 \%(11)$ \\
\hline Mégret & .28 & $13.8 \%(10)$ & $2.3 \%(12)$ \\
\hline Taubira & .08 & $12.6 \%(13)$ & $2.3 \%(13)$ \\
\hline Lepage & .52 & $13.4 \%(12)$ & $1.9 \%(14)$ \\
\hline Boutin & .17 & $6.7 \%(15)$ & $1.2 \%(15)$ \\
\hline Gluckstein & .16 & $5.5 \%(16)$ & $0.4 \%(16)$ \\
\hline
\end{tabular}

Table 6: France: Candidate first round levers and estimated approvals

dicts that, under approval voting, Le Pen would have fallen from the second place to the third or fourth place.

The conclusions are that the hierarchy of candidates is modified, even if Jacques Chirac remains quite clearly the winner. The detail of who is winning and who is losing in this game is complex and requires candidate-specific explanations related to the particular political situation for this election. For instance, the analysis confirms that many voters who approved Jospin decided to vote for Chevènement at the official first round ; maybe the main direct cause of Jospin's defeat (Jaffré 2003).

Analysis performed by Baujard and Igersheim after the 2007 election also conclude in the same direction: compared with two-round majority voting, Approval Voting, and Range Voting with the $0-1-2$ scale favor the centrist candidates.

The method of the single-name levers is far from being totally satisfactory when applied - as we did - to a small number of voting stations. It should be improved but it hopefully corrects part of the important biases which are inherent to the "field test" methodology. 


\subsection{The Political Space}

A ballot designed to approve, to rank, or to grade candidates contains more information than a single-name ballot. For instance with approval voting, one knows after the election not only the candidate scores, but also how many voters approved both candidates $\mathrm{A}$ and $\mathrm{B}$. With voting rules based on individuals ranking candidates, we know how many voters rank $\mathrm{A}$ above B. This data set is thus worth analyzing.

Such an analysis has been done on the data collected in 2002 with approval voting (Laslier and Van der Straeten 2002, Laslier 2006) using ad hoc variants of Multidimensional Scaling. ${ }^{6}$ The basic idea is that two candidates are close one from the other if they tend to be approved by the same voters. This is a very meaningful - and simple - notion of political proximity among candidates, which can be expressed on the basis of the votes only, without reference to some exogenous "issue space."

The question of the participation bias is still important, so some analysis are restricted to the study of Gy-Les-Nonains, where the almost complete participation makes the data set particularly valuable. Of course extrapolation is not meaningful but at least, we learn about French politics, as seen from this village, and that is interesting by itself. The results are not surprising to those who know the political landscape in France in 2002: a strong Left-Right separation, with Jacques Chirac in the middle of the galaxy of the right-wing candidates and the so-called "center" being in fact one component of this galaxy.

The remark that those kind of analysis can be made on the basis of real voting ballots can be considered as another argument in favor of the use of voting rules in which the voter officially provides more information than the name of a unique candidate. The fact is that an election does not only serve to chose one or several winners. The result are also analyzed and commented by academics, journalists and citizens because it is a privileged occasion to learn about the country or the district. In that perspective, who could argue against obtaining a more detailed information ?

\section{Conclusions}

Our objectives when running these experiments were manifold.

\footnotetext{
${ }^{6}$ Laslier (1996, 2003) developped the same tools for analyzing ranking ballots. LeRoux and Rouanet (2004) is a modern introduction to the methods of Geometric Data Analysis. Chiche et al. (2000) is an application.
} 
Public reaction to experimentation in political science. It is interesting to know how the public would react to the use of experimentation about politics and elections. In that respect, there is no doubt that these experiments are very successful. People are curious about it and ready to take part. They show very little hostility towards the idea of experimenting in politics.

Understanding voting rules. People who accept to take part in such an experiment understand the instructions, with a possible difficulty, in some cases, with incomplete ballots. Unfortunately, we do not learn from these experiments wether they understand the way ballots are counted. This is not a problem for rules using simple counting schemes, but it is a problem for complex evaluative or ranking ballots.

Learning about voter behavior. The theory of how people vote under different voting rules is far from complete; so, one goal of the experiments should be to observe voters' behavior at the individual level. The experimental elections on the field are not well suited for this goal because we cannot relate to the voter's vote any personal characteristic, whether her/his true vote, or her/his true ranking (or evaluation) of candidates, or her/his social and economic characteristics.

Learning about aggregate results. Many authors insist on the fact that different voting rules may yield different outcomes. Yet, little empirical evidence is provided to support this idea on large scale elections. After eliminating (important) sample bias Laslier and Van der Straeten, and Baujard and Igersheim have shown that Approval voting and $0-1-2$ range voting tends to favor consensus candidates.

Learning about French politics. The low approval rates and the low evaluations obtained by candidates show that even elected candidates (Chirac, Sarkozy) do not have a huge support in the population. Under Approval Voting, no candidate is able to be approved by half of the electorate. More detailed information can be obtained on the structure of the political space. For instance, with Approval Voting, since each voter could select the names of several candidates on the same ballot, we know how many voters approved each group of candidates. We can infer some information on "correlations" between candidates - two candidates being "close" when voters treat them alike: the same voters vote for both of them or for none of them.

\section{References}

[1] Carlos Alós-Ferrer and Đura-Georg Granić (2009) "Approval Voting in Germany: Description of a Field Experiment" mimeo., university of 
Konstanz.

[2] Michel Balinski and Rida Laraki (2007) "Election by Majority Judgement: Experimental Evidence." Cahier du Laboratoire d'Econométrie de l'Ecole Polytechnique, December 2007, n 2007-28.

[3] Balinski, M., R. Laraki, J.-F. Laslier and K. Van der Straeten (2003), "Le vote par assentiment : une expérience", Cahier du Laboratoire d'Econométrie de l'Ecole Polytechnique, N 2003-13.

[4] Balinski, M., J.-F. Laslier and K. Van der Straeten (2002) « Compterendu d'une expérience de vote à l'Institut d'Etudes Politiques » mimeo., école polytechnique.

[5] Antoinette Baujard and Herrade Igersheim (2007) « Expérimentation du vote par approbation et du vote par note lors des élections présidentielles françaises du 22 avril 2007. Analyses. »Centre d'Analyse Stratégique, Paris.

[6] Virginie Béhue, Pierre Favardin, and Dominique Lepelley (2009) « La manipulation stratégique des règles de vote : une étude expérimentale» forthcoming in Recherches Economiques de Louvain.

[7] André Blais, Jean-François Laslier, Annie Laurent, Nicolas Sauger and Karine Van der Straeten (2007) "One round versus two round elections: an experimental study" French Politics 5: 278-286.

[8] André Blais, Simon Labbé-St-Vincent, Jean-François Laslier, Nicolas Sauger and Karine Van der Straeten (2008) "Vote choice in one round and two round elections", document de travail, Ecole Polytechnique.

[9] André Blais, Jean-François Laslier, Nicolas Sauger and Karine Van der Straeten (2009) "Sincere, Strategic, and Heuristic Voting under four Election Rules: An Experimental Study", document de travail, Ecole Polytechnique.

[10] Brams, S. and P. Fishburn (2001) "A nail-biting election" Social Choice and Welfare 18:409-414.

[11] Brams, S. and P. Fishburn (2005), "Going from theory to practice: the mixed success of Approval Voting", Social Choice and Welfare 25: $457-474$. 
[12] Chiche, J. B. Le Roux, P. Perrineau and H. Rouanet (2000) "L'espace politique des électeurs francais à la fine des années 90" Revue francaise de sciences politiques 50: 463-487.

[13] Davis D. and C. Holt (1993), Experimental Economics, Princeton: Princeton University Press.

[14] J. Jaffré, « Comprendre l'élimination de Lionel Jospin », in P. Perrineau et C. Ysmal (dir.), Le vote de tous les refus, Presses de Science Po, Paris, 2002.

[15] David M. Farrell (2001) Electoral Systems Palgrave.

[16] Farvaque, E., Jayet, H., and Ragot, L. (2009) "Quel mode de scrutin pour quel vainqueur? Une expérience sur le vote préférentiel transférable" forthcoming in Revue d'Economie Politique.

[17] Fiorina, M. and C. Plott (1978), "Committee decisions under majority rule : An empirical study", American Political Science Review, 72: $575-598$.

[18] Green D., and A. Gerber (2002), "Reclaiming the experimental tradition in Political Science", in I. Katznelson and H. Milner (eds.), State of the Discipline in Political Science, New York: Norton.

[19] Alan S. Gerber, Donald P. Green, and Christopher W. Larimer (2008) "Social Pressure and Voter Turnout: Evidence from a Large Scale Field Experiment" American Political Science Review 102: 33-48.

[20] Sebastian Kube and Clemens Puppe (2009) "(When and How) Do Voters Try to Manipulate ?" Public Choice 139: 39-52.

[21] Laslier, J.-F. (1996) "Multivariate analysis of comparison matrices" Multicriteria Decision Analysis 5: 112-126.

[22] Laslier, J.-F. (2003) "Analyzing a preference and approval profile" Social Choice and Welfare 20:229-242.

[23] Laslier, J.-F. (2006) "Spatial approval voting" Political Analysis 14: 160-185.

[24] Laslier, J.-F. and K. Van der Straeten (2002) "Analyse d'un scrutin d'assentiment" Quadrature 46:5-12. 
[25] Laslier, J.-F. and K. Van der Straeten (2004) "Vote par assentiment pendant la présidentielle de 2002: analyse d'une expérience", Revue française de science politique 54 : 99-130.

[26] Laslier, J.-F. and K. Van der Straeten (2008) "A live experiment on approval voting" Experimental Economics 11: 97-105.

[27] LeRoux, Brigitte, and Henry Rouanet (2004) Geometric Data Analysis. Dordrecht: Kluwer.

[28] McKelvey, R. and P. Ordeshook (1990), "A decade of experimental research on spatial models of elections and committees", in J. Enelow and M. Hinich (eds.), Readings in the Spatial Theory of Voting, Cambridge: Cambridge University Press.

[29] R. Forsythe, T. A. Rietz, Roger Myerson and Robert J. Weber (1993) "An Experiment on Coordination in Multicandidate Elections: the Importance of Polls and Election Histories" Social Choice and Welfare 10: 223-247.

[30] R. Forsythe, T. A. Rietz, Roger Myerson and Robert J. Weber (1996) "An Experimental Study of Voting Rules and Polls in Three-Way Elections" International Journal of Game Theory 25: 355-383.

[31] Saari, D. (2001) "Analyzing a nail-biting election" Social Choice and Welfare 18:415-430.

[32] Wantchekon, L. (2003), "Clientelism and Voting Behavior: Evidence from a Field Experiment in Benin", World Politics, 55: 399-422. 